\title{
Endometrial Aspiration Cytology by Karman’s Cannula with Histopathological Correlation
}

\author{
Jyoti Bikash Saikia', Adity Sharma \\ ${ }^{1}$ Demonstrator, Department of Pathology, Assam Medical College, Dibrugarh, Assam \\ ${ }^{2}$ Professor, Department of Pathology, Assam Medical College, Dibrugarh, Assam
}

\begin{abstract}
Introduction: Dilatation and curettage is the commonly used diagnostic technique to assess endometrial normalcy and pathology. Endometrial aspiration cytology on the other hand is a simple outpatient procedure without the cost of hospitalization, operation theatre \& risk of anesthesia inherent in dilatation and curettage. Objectives: The present study was carried out carried out to assess the sensitivity and specificity of endometrial cytology performed by using Karman's cannula compared with histopathology. Materials \& Method: Endometrial aspiration was done using $4 \mathrm{~mm}$ Karman's cannula in 144 cases who presented with dysfunctional uterine bleeding, postmenopausal bleed and infertility prior to dilatation and curettage. The cytological diagnosis was correlated with histopathological diagnosis. Results: Adequate material was obtained in $93.06 \%$ of cases on aspiration. Proliferative endometrium was the most common pattern (38.2\%) observed. There was an overall $100 \%$ correlation in case of secretory endometrium, atypical hyperplasia and endometrial carcinoma and $90.9 \%$ correlation in case of proliferative endometrium between cytological and histopathological findings. The sensitivity and specificity of endometrial aspiration was $88.31 \%$ and $100 \%$ respectively. Conclusion: Endometrial aspiration was found to be simple, safe, cost effective, well tolerated outpatient procedure which can be offered to patients as an outpatient sampling technique.
\end{abstract}

Keywords: Endometrial Aspiration Cytology, Karman's Cannula, Endometrial Carcinoma

\section{Introduction}

Endometrial aspiration cytology is an effective method for ensuring endometrial normalcy, cytohormonal evaluation of the endocrine status and for diagnosing malignant and premalignant states. However direct cytological sampling and examination of the endometrium is not generally practiced, which is surprising as the endometrium is exceedingly easy to sample. ${ }^{[1]}$

Aspiration cytology is a safe, simple and reliable technique without any complication and can be used as a safe and reliable out-patient procedure with minimum discomfort to the patient. ${ }^{[2]}$ Hysteroscopy directed endometrial biopsy of suspicious lesions is the gold standard investigation but is invasive, needs specialized equipment and is operator dependent. ${ }^{[3]}$ It also involves the cost of hospitalization and operation theaters, bed shortages and risk of anesthesia and operative complications which can be avoided by aspiration cytology. ${ }^{[4]}$

The development of a technique for sampling the endometrium was encouraged by Papanicolaou himself, who acknowledged the inadequacy of the cervical smear for detecting endometrial pathologies. Thus, many attempts were made by authors to find out a simple and accurate method to obtain the endometrial sample. These authors concluded that endometrial aspiration technique was an acceptable and valuable method of assessing the endometrium which can be taken up as an OPD procedure. $[5,6]$

In this study an attempt was made to evaluate the sensitivity and specificity of endometrial aspiration cytology using a Karman's cannula taking histologic findings as gold standard.

\section{Materials and Methods}

The study was carried out for a duration of 1 year and 144 cases were sampled. Thorough clinical history and general systemic and local examination were done for each case. Informed consent of the patients was obtained before the diagnostic procedure, endometrial aspiration cytology followed by diagnostic curettage. Endometrial aspiration was performed by a plastic disposable Karman's cannula measuring $4 \mathrm{~mm}$ by the pathologist in the gynecology theater under supervision of the gynecologist and without administrating anesthesia. The cannula was inserted into the endometrial cavity and connected to 20cc disposable syringe. Negative pressure was then created by withdrawing the piston and maintained, while the mucosa was uniformly aspirated. The suction was released after aspiration and the cannula was withdrawn. After removal of the cannula, the surface was wiped to avoid contamination by cervical and vaginal cells. The material was expressed on a clean glass slide; the type of specimen aspirated is noted and then smeared. Then it was immediately fixed in a fixative $(90 \%$ alcohol).

In the same sitting, immediately after aspiration, the gynecologist obtains endometrial biopsy and fixed in $10 \%$ formaldehyde. After the biopsy, the patient was observed and evaluated for vaginal bleeding at least for 15 minutes.

The cytology slides were stained by Papanicolaou stain. The specimen for histology were taken through the necessary steps and then stained with hematoxylin \& eosin. The results of endometrial aspiration cytology and histopathology were compared. All data was analyzed manually, and with the help of SPSS and Excel software. 


\section{International Journal of Science and Research (IJSR) \\ ISSN (Online): 2319-7064}

Index Copernicus Value (2016): 79.57 | Impact Factor (2015): 6.391

\section{Results}

Among 144 patients examined, most women were in the age group of $36-45(41.7 \%)$, followed by $46-55$ years $(40.3 \%)$. There were $17.4 \%$ and. $7 \%$ in $<35$ years and $>55$ years age groups respectively. 85 cases were in reproductive age group and 6 cases were postmenopausal, the rest of the cases belonged to peri menopausal age group. Only 10 samples were inadequate for opinion, of which 6 samples were mucoid and 4 samples were hemorrhagic on gross examination and 5 samples were reported as proliferative phase, 2 as simple hyperplasia, 2 as endometritis and 1 as atrophic endometrium on histopathology.

Cytological examination of 85 cases in the reproductive age group showed that 44 cases were reported as proliferative phase, 5 cases as secretory phase, 19 cases as simple hyperplasia, 1 case as complex hyperplasia, 4 cases as atypical hyperplasia, 5 cases as endometritis, 1 case as granulomatous endometritis and 3 cases as endometrial adenocarcinoma and aspirate material of 3 cases were in adequate for diagnosis.

In premenopausal and postmenopausal age group, out of 59 cases, 15 cases had proliferative phase, 2 cases belonged to secretory phase, 29 cases had endometrial hyperplasia, of which 1 case was reported as atypical hyperplasia. 2 cases were reported as endometrial adenocarcinoma and 7 cases had inadequate material for interpretation. 2 cases were reported as atrophic endometritis. The remaining 2 cases were reported as non-specific endometritis.

Proliferative endometrium was the most common pattern both on histopathology (38.19\%) as well as endometrial aspiration cytology (40.97\%). There was $100 \%$ cyto-histo correlation in cases of secretory endometrium, specific endometritis, atypical hyperplasia and endometrial adenocarcinoma. $90.90 \%$ cases of proliferative endometrium could be diagnosed on cytology. 5 cases were missed due to inadequacy.

The histo-cyto correlation in case of atrophic endometrium and nonspecific endometritis were $66.7 \%$ and $77.8 \%$ respectively. The diagnoses missed were due to inadequacy.

All the cases of atypical endometrial hyperplasia were correctly detected by cytology. However, $76.60 \%$ cases of simple hyperplasia could be correctly diagnosed by cytology. Endometrial aspiration cytology was unable to diagnose 11 cases of simple hyperplasia, 9 of which were reported as proliferative phase on histopathology. Other 2 cases were inadequate for reporting. Also, endometrial cytology detected only 4 out of the 12-complex hyperplasia reported on histopathology. All the misdiagnosed cases were reported as simple hyperplasia on cytology.

On cyto-diagnosis total 5 cases were reported as malignancies of which all 5 correlated well with histological diagnosis of endometrial adenocarcinoma, with correlation of $100 \%$.
Table 1: Correlation of Cytological and Histological Findings

\begin{tabular}{|c|c|c|c|c|}
\hline Diagnosis & $\begin{array}{c}\text { Number of } \\
\text { cases } \\
\text { diagnosed on } \\
\text { cytology }\end{array}$ & $\begin{array}{c}\text { Number of } \\
\text { cases } \\
\text { proved on } \\
\text { histology }\end{array}$ & $\begin{array}{c}\text { Number } \\
\text { of cases } \\
\text { matched }\end{array}$ & $\begin{array}{c}\text { Percentage } \\
(\%) \\
\text { of } \\
\text { Correlation }\end{array}$ \\
\hline $\begin{array}{c}\text { Proliferative } \\
\text { Phase }\end{array}$ & 59 & 55 & 50 & 90.90 \\
\hline Secretory Phase & 7 & 7 & 7 & 100.00 \\
\hline $\begin{array}{c}\text { Atrophic } \\
\text { Endometrium }\end{array}$ & 2 & 3 & 2 & 66.67 \\
\hline $\begin{array}{c}\text { Non-Specific } \\
\text { Endometritis }\end{array}$ & 7 & 9 & 7 & 77.78 \\
\hline $\begin{array}{c}\text { Specific } \\
\text { Endometritis }\end{array}$ & 1 & 1 & 1 & 100.00 \\
\hline $\begin{array}{c}\text { Simple } \\
\text { Hyperplasia }\end{array}$ & 44 & 47 & 36 & 76.60 \\
\hline $\begin{array}{c}\text { Complex } \\
\text { Hyperplasia }\end{array}$ & 04 & 12 & 4 & 33.33 \\
\hline $\begin{array}{c}\text { Atypical } \\
\text { Hyperplasia }\end{array}$ & 5 & 5 & 5 & 100.00 \\
\hline $\begin{array}{c}\text { Endometrial } \\
\text { Carcinoma }\end{array}$ & 5 & 5 & 5 & 100.00 \\
\hline TOTAL & 134 & 144 & 117 & - \\
\hline
\end{tabular}

\section{Statistical Analysis}

Out of the 134 valid cases, 66 cases were reported as cyclic or normal endometrium and 68 cases abnormal endometrium on cytology. On histopathology 57 cases were reported as cyclic endometrium and 77 cases were reported as abnormal endometrium. These data were further used for statistical analysis.

Table 2: Statistical Analysis in present study

\begin{tabular}{|c|c|c|c|c|}
\hline \multirow{2}{*}{$\begin{array}{l}\text { Cytologic } \\
\text { diagnosis }\end{array}$} & \multicolumn{2}{|c|}{ Histologic diagnosis } & \multirow[t]{2}{*}{ Total } & \multirow[t]{2}{*}{$P$-value } \\
\hline & Positive & Negative & & \\
\hline Positive & 68 & 0 & 68 & \multirow[t]{2}{*}{$<0.0001$} \\
\hline Negative & 9 & 57 & 66 & \\
\hline TOTAL & 77 & 57 & 134 & \\
\hline
\end{tabular}

- Sensitivity $=88.31 \%$

- Specificity $=100 \%$

- Positive Predicted value $(\mathrm{P}+)=100 \%$

- Negative Predicted value $(\mathrm{P}-)=86.36 \%$

- Accuracy $=93.29 \%(50.75 \%+42.54 \%)$

Statistical analysis of endometrial aspiration study of 134 samples showed that it has a high specificity (100\%), positive $(100 \%)$ and negative $(86.36 \%)$ predictive values. The sensitivity of this technique was $88.31 \%$. The accuracy of the test was $93.29 \%$ and a highly significant $(p<0.001)$ statistical relation was observed between histopathology and cytopathology.

\section{Discussion}

Traditionally the standard method of assessing the endometrium has always been dilation of the cervix and curettage of the uterine cavity under general anesthesia. It accounts for a large proportion of hospital bed use and operating room time. The cost is significant and also carries the complication of anesthesia. Therefore, alternative procedures of endometrial sampling like endometrial brush,

\section{Volume 6 Issue 12, December 2017}




\section{International Journal of Science and Research (IJSR) \\ ISSN (Online): 2319-7064}

Index Copernicus Value (2016): 79.57 | Impact Factor (2015): 6.391

Endocyte, Endo-pap sampler, membrane filtration method, endometrial Gravlee-jet washers, Isaacs's endometrial cell sampler, Mi-Mark Helix, lippies loop method and disposable plastic cannula were adopted. For a cytological technique to be accepted as a useful tool for endometrial screening it must first be proven to be an inexpensive, simple (can be used by any gynecologist) and painless sampling method that is able to obtain representative endometrial cells. Secondly, it must be shown that accurate interpretation of samples is possible. ${ }^{[7]}$

With this in mind, uterine aspiration cytology, an ambulatory procedure for endometrial sampling was studied. Often endometrial lesions are focal in distribution. A single strip biopsy may miss the lesion, but by application of this technique, more representative samples of endometrium can be obtained. Studies have revealed that, at times even when curettage findings have been normal, endometrial aspiration cytology has been found to be useful for diagnosing endometrial pathology. ${ }^{[8]}$ Outpatient sampling of the Endometrium could complement conventional curettage and assist in patient management.

Endometrial aspiration cytology was performed using $4 \mathrm{~mm}$ Karman's cannula in our study and we found it to be acceptable as an outpatient procedure with only mild to moderate discomfort in most of the patients. Complications like hemorrhage, infection or perforation following the procedure were also absent.

When sample adequacy of Karman's cannula was compared with other similar devices, results are on a par. Liza et al used the insemination cannula for intrauterine aspiration, with sensitivity of $81.6 \%$ and specificity of $83.3 \%$. ${ }^{[9]}$ Malik et al used insemination cannula of $0.5 \mathrm{~mm}$ diameter for aspiration sampling reported successful sampling of $96 \%$.[2] In 2010 Upadhyaya I. and Malla D.S. used pediatric feeding tube for sampling and reported successful sampling of $95.29 \% .{ }^{[10]}$ Also in 2014 Samina Ashraf and Farhat Jabeen using Karman's cannula reported an adequacy rate of $93.4 \% .^{[11]}$

In our experience using Karman's cannula, adequate material was obtained in $93.06 \%$ of the cases which rank well when compared with other studies. The cellular morphology was well maintained in all the smears.

The study conducted by Dowling et al using Gravlee jet washer had inadequacy rate of $27 \% .^{[12]}$ Isaac reported the inadequacy rate of $2.5 \% .^{[13]}$ In the study conducted by Afonso et al, using Gravlee jet washer, the inadequacy rate was $1.6 \%$ and Liza et al $2.8 \% .{ }^{[9,14]}$ Samina Ashraf and Farhat Jabeen using Karman's cannula reported an inadequacy rate of $6 \% .{ }^{[11]}$ The various causes of inadequacy of cellular fluid in endometrial aspiration cytology are due to atrophic Endometrium, cervical stenosis, difficulty in insertion, poor technique, drying artifact, etc.

In our study, aspirated material was inadequate for interpretation in $7 \%$ of cases, which is comparable to Malik et al and results of Samina Ashraf and Farhat Jabeen. ${ }^{[2,11]}$ We considered that the major causes of inadequacy in our case are atrophic endometrium and technique failure.
If we consider type of aspirate, among the all 144 cases, hemorrhagic type was the most common $(87.5 \%)$ and there was only one purulent aspirate which turned out to be a case of endometrial carcinoma. Hemorrhagic aspirates were found to have a high adequacy rates $(96.8 \%)$ and mostly reported as cyclic endometrium (43.65\%). Hemorrhagic aspirates with tissue fragment were all (11 of 144 cases) were reported as hyperplasia in $81.8 \%$ of the cases. All mucoid aspirates $(4.2 \%)$ were reported inadequate on examination.

Malik et al reported hemorrhagic aspirate as the most common finding and $96 \%$ of which was cyclic endometrium, $2 \%$ as hyperplasia and $2 \%$ as inadequate. All aspirates showing hemorrhagic aspirate with tissue fragment were reported as hyperplasia. Mucoid and serous aspirates were found inadequate and purulent aspirate as adenocarcinoma. ${ }^{[2]}$ In the study conducted by Samina Ashraf and Farhat Jabeen hemorrhagic aspirates were reported to have a high adequacy rate. They also reported hemorrhagic aspirate was most common and $84.2 \%$ of which was reported as cyclic endometrium. In mucoid aspirates $50 \%$ were reported as inadequate and $50 \%$ as proliferative endometrium. ${ }^{[11]}$ Thus, the results are in agreement with the findings of Malik et al and Samina Ashraf and Farhat Jabeen. ${ }^{[2,11]}$

The accuracy of major cytological diagnoses in the present study when compared to methods used by other authors are presented in the table 3. A correlation of $90.90 \%$ was observed for proliferative phase similar to Ambiye et al and Malik et al. ${ }^{[2,15]}$ An accuracy of $100 \%$ was observed for secretory phase, in the present study, which is comparable to Malik et al and Upadhyaya I., Malla D.S. ${ }^{[2,10]}$ Accuracy of $70.31 \%$ was observed in diagnosis of hyperplasia, including simple hyperplasia (76.70\%), complex hyperplasia $(33.33 \%)$ and atypical hyperplasia (100\%) similar to that of Schachter et al of $77 \%$ and Malik et al $(67 \%) .{ }^{[2,16]}$

Table 3: Correlation between endometrial cytology and histology in various series

\begin{tabular}{|c|c|c|c|c|}
\hline Authors & $\begin{array}{c}\text { Proliferative } \\
\text { Phase }\end{array}$ & $\begin{array}{c}\text { Secretory } \\
\text { Phase }\end{array}$ & $\begin{array}{c}\text { Endometrial } \\
\text { Hyperplasia }\end{array}$ & $\begin{array}{c}\text { Endometrial } \\
\text { Carcinoma }\end{array}$ \\
\hline $\begin{array}{c}\text { Ambiye } \text { et al } \\
(1981)\end{array}$ & 88.00 & 88.0 & - & - \\
\hline $\begin{array}{c}\text { Schachter } \text { et al } \\
(1980)\end{array}$ & 86.40 & 78.50 & 77 & 100 \\
\hline $\begin{array}{c}\text { Liza } \text { et al } \\
\text { (1990) }\end{array}$ & 100.00 & 82.30 & 82.6 & 100 \\
\hline $\begin{array}{c}\text { Malik } \text { et al } \\
\text { (2008) }\end{array}$ & 87.40 & 100.0 & 67 & 100 \\
\hline $\begin{array}{c}\text { Upadhyaya I. } \\
\text { and Malla D.S. } \\
\text { (2010) }\end{array}$ & 98.11 & 97.17 & 100 & - \\
\hline $\begin{array}{c}\text { Samina Ashraf } \\
\text { and Farhat } \\
\text { Jabeen (2014) }\end{array}$ & 96.00 & 90.90 & 96.96 & - \\
\hline $\begin{array}{c}\text { Present Study } \\
\text { (2014) }\end{array}$ & 90.90 & 100.0 & 70.31 & 100 \\
\hline
\end{tabular}

On cytology, the diagnosis of hyperplasia could be made but the type of hyperplasia was successfully interpreted only in $33.33 \%$ in case of complex hyperplasia and $76.70 \%$ in case of simple hyperplasia. Intact glandular structures with 


\section{International Journal of Science and Research (IJSR) \\ ISSN (Online): 2319-7064}

Index Copernicus Value (2016): 79.57 | Impact Factor (2015): 6.391

preserved architecture if present on smear provide valuable clues to diagnosis between simple and complex hyperplasia. The use of cell block technique with cytology smear have been suggested which can provide important information about the architecture. [17] Recently Noritmatsu et al published interesting results using an Endocyte sampler device. They propose new diagnostic criteria based on the composition and architecture of tissue fragments. Cell aggregates with a tube or sheet-shaped pattern were found in $97.5 \%$ of samples of normal proliferative endometrium. In Endometrial hyperplasia, cell aggregates with a dilated or branched pattern were found in $34.9 \%$ of cases. ${ }^{[8]}$

The cytological differentiation between atypical hyperplasia and endometrial adenocarcinoma was another difficulty that we faced. This issue was discussed in two sessions at the XV International Congress of Cytology, (Santiago de Chile, 2004), 'The Jiménez-Ayala Classification' was proposed by Jiménez-Ayala $M$ which divided endometrial proliferative lesions as endometrial hyperplasia and endometrial neoplasia. Endometrial hyperplasia included both simple and complex hyperplasia and endometrial neoplasia included atypical hyperplasia and well differentiated endometrial carcinoma. ${ }^{[18]} \mathrm{We}$ strongly agree with the use of this classification.

An accuracy of $77.78 \%$ was observed when diagnosis of endometritis was made. 7 cases out of 9 when compared with histopathology. One case was diagnosed as tubercular endometritis both on histopathology and cytology with a correlation of $100 \%$. A study by Padubidri et al showed $100 \%$ accuracy of tubercular endometritis. Triparty SN, Mahanty J. (1990), Padubidri et al and V. Malhotra (1996) found a $100 \%$ correlation in case of tuberculous endometritis. The findings of present study are in agreement the findings of these authors. ${ }^{[19,20,21]}$

The incidence of tuberculosis in India is high when compared to western countries and tubercular endometritis is considered a common cause of infertility. The combination to endometrial aspiration cytology and endometrial biopsy is recommended as an outpatient sourcing procedure in such cases where the rate of tuberculosis is high.

Atrophic Endometrium was reported in 3 cases. 2 cases diagnosed on cytology were confirmed by histopathology and a correlation of $66.67 \%$ was observed. Upadhyaya I. and Malla D.S. reported a $100 \%$ correlation, however only one case was detected in the study. Samina Ashraf and Farhat Jabeen reported $82.4 \%$ correlation in case of atrophic endometrium. In atrophic Endometrium, shedding of Endometrium is less, so some aspirates are sometimes reported inadequate for interpretation. The findings of present study are in agreement the findings of Samina Ashraf and Farhat Jabeen in case of atrophic endometrium. [10,11]

In the present study, 5 cases of malignancy were diagnosed as endometrial adenocarcinoma on cytology and were confirmed by histology. The correlation was $100 \%$, and the results are similar to findings of other authors. ${ }^{[2,9,16]}$
The sensitivity and specificity reported in the present study by using Karman's cannula when compared to methods used by other authors is summarized in the table 4. Samina Ashraf and Farhat Jabeen in their study used the Karman's cannula with a sensitivity and specificity of $91.9 \%$ and $100 \% .{ }^{[11]}$ In the present study too, the Karman's cannula was used which gave a sensitivity of $83.31 \%$ and a specificity of $100 \%$. Similar studies done by An-Foraker et al, Bistoletti et al, Liza et al and Malik et al by using different devices as the Isaac cell sampler, Endo-pap sampler and Insemination cannula with sensitivity of 81.62$96.15 \%$ and specificity of $95.5-100 \% .^{[2,9,22,23]}$

Table 4: Sensitivity and specificity in various series compared with present study

\begin{tabular}{|c|c|c|c|}
\hline Authors & $\begin{array}{c}\text { Method used for } \\
\text { intrauterine washing }\end{array}$ & $\begin{array}{c}\text { Sensitivity } \\
(\%)\end{array}$ & $\begin{array}{c}\text { Specificity } \\
(\%)\end{array}$ \\
\hline An-Foraker et al & Isaac cell sampler & 96.15 & 96.85 \\
\hline Bistoletti et al & Endo-pap sampler & 97 & 84 \\
\hline Liza et al & Insemination cannula & 81.62 & 83.33 \\
\hline Malik et al & Insemination cannula & 83.3 & 95.4 \\
\hline $\begin{array}{c}\text { Samina Ashraf, } \\
\text { Farhat Jabeen }\end{array}$ & Karman's cannula (4mm) & 91.9 & 100 \\
\hline Present study & Karman's cannula (4mm) & 83.31 & 100 \\
\hline
\end{tabular}

\section{Conclusion}

Endometrial aspiration was found to be simple, safe, cost effective, well tolerated outpatient procedure in the diagnosis of abnormal and normal endometrium for patients of all ages.

While not completely replacing the conventional D\&C, endometrial aspiration still has few advantages.

- It is a simple, inexpensive outpatient procedure with no complication \& well tolerated by patients.

- Adequacy of material is high.

- It has got high accuracy in phasing the endometrium \& assessing the cytohormonal status.

- It can also detect endometrial pathologies like endometrial hyperplasia, atrophy, atypia and malignancy even when focal in nature.

Therefore, at the end of this study, we propose that endometrial aspiration cytology can be used as a screening procedure for early detection of various endometrial diseases, thereby leading to a better prognostic outcome.

\section{References}

[1] Maksem JA, Robboy SJ, Bishop JW, Meiers I. Endometrial Cytology with Tissue Correlations. In: Dorothy L. Rosenthel, editor. Essentials in Cytopathology Series, 1st edn. New York: Springer; 2009: p.1.

[2] Malik R, Agarwal R, Tandon P. Cytological assessment of endometrial washings obtained with an insemination cannula and it histological correlation. Journal of cytology, October 2008; 25: 128-32.

[3] Hunter D.C, Mc Clure N. Abnormal uterine bleeding. An evaluation by endometrial biopsy, vaginal ultrasound and outpatient hysteroscopy. The Ulster Medical Journal 2001 May; 70(1):25-30. 


\section{International Journal of Science and Research (IJSR) \\ ISSN (Online): 2319-7064 \\ Index Copernicus Value (2016): 79.57 | Impact Factor (2015): 6.391}

[4] Sagar S, Prakash P, Goyal U. A histo-cytologic study of endometrium by aspiration technique. J of Obst \& Gyn of India 1980; 26(1): 626- 29.

[5] Hecht EL. The endometrial aspiration smear; research status and clinical value. Am J Obst \& Gynaec 1956; 71(4): 819- 33.

[6] Polson DW, Morse A, Beard RW. An alternative to the diagnostic dilatation and curettage- endometrial cytology. Br Med J 1984; 288: 981- 83.

[7] Palermo VG: Interpretation of endometrium obtained by the Endopap sampler and a clinic study of its use. Diagn Cytopathol. 1985; 1: 15-12.

[8] Norimatsu Y, Shimizu K, Kobayashi TK, Moriya T, Tsukayama C, Miyake Y Et al. Cellular features of endometrial hyperplasia and well-differentiated adenocarcinoma using the Endocyte sampler. Diagnostic criteria based on the cytoarchitecture of tissue fragments. Cancer Cytopathol 2006; 108: 77-85.

[9] St. Liza, Kumar R, St. Lilian K. Value of endometrial aspiration cytology in assessing endometrial status in symptomatic Peri and Postmenopausal women. Indian J. Cancer. March 1999; 36(1): 57-61.

[10] Upadhaya I, Malla DS. Endometrial aspiration cytology is comparable with Endometrial Biopsy in case of women with abnormal uterine bleeding. PMJN 2009; $8(2)$.

[11] Ashraf S, Farhat J. A Comparative Study Of Endometrial Aspiration Cytology With Dilatation And Curettage In Patients With Dysfunctional Uterine Bleeding, Peri menopausal And Postmenopausal Bleeding. JK- Practitioner; 2014; January-June: 19(2): 41- 5 .

[12] Dowling EA, Gravlee LC, Hutchins KE. A new technique for the detection of adenocarcinoma of the endometrium. Acta Cytol 1969; 13:496-501.

[13] Isaacs J, Wilhoitte R. Aspiration cytology of the endometrium: office and hospital sampling procedures. Obstet Gynecol 1974; 118: 679- 87.

[14] Afonso JF. Value of Gravlee Jet Washer in the diagnosis of endometrial cancer. Obstet Gynecol 1975; 46: $141-6$.

[15] Ambiye VR, Alwani CM, Sinha R. Single Endometrial Aspiration J. Obstet. Gynecol of India. 1984; 899-901.

[16] Schachter A, Balerman A, Bahary C, Cohen SJ. The value of cytology in the Diagnosis of Endometrial Pathology. Acta Cytologica. March - April, 1980, 24(2):149- 52.

[17] Coscia-Porrazzi LO: Cytologic criteria of hyperplastic lesions in endometrial samples obtained by the Endocyte sampler. Diagn Cytopathol 1988; 4: 283-87.

[18] Jiménez-Ayala M, Jiménez-Ayala B: Introduction. Value of endometrial cytology. Panel on Endometrial Adenocarcinoma. Prevention and Early Diagnosis. XV International Congress of Cytology, Santiago de Chile 2004.

[19] Tripathy SN, Mahanty J. Place of aspiration cytology in dysfunction uterine bleeding. J Indian Med Assoc 1990; 88(9): 247- 48.

[20] Padubidri V, Baijal L, Prakash P, Chandra K. The detection of endometrial tuberculosis in cases of infertility by uterine aspiration cytology. Acta Cytol. 1980; Jul -Aug: 24 (4): 319-29.

[21] Malhotra V. Role of endometrial aspiration cytology in infertility. Journal of Obstetrics and Gynecology of India 1996; 46:110-14.

[22] An-Foraker SH, Kawada CY, McKinney D. Endometrial aspiration studies on Isaacs cell sampler with cytohistologic correlation. Acta Cytol 1979; 23:303-8

[23] Bistoletti P, Hjerpe A. Routine Use of Endometrial Cytology in Clinical Practice. Acta Cytologica. November - December 1993; 37, Number 6: 867- 70.

\section{Author Profile}

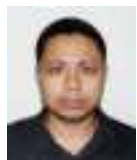

Dr. Jyoti Bikash Saikia currently working as demonstrator of Pathology, Assam medical college, Dibrugarh Assam. His interests are primarily gynecological cytology and hematology.

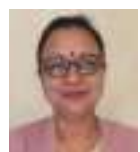

Dr. Adity Sharma currently working as Professor of Pathology and Director in-charge State of the art model blood Bank, Assam Medical college, Dibrugarh, Assam. She has been a mentor to many Postgraduate students and has many noteworthy publications in the field of cytology. 